\title{
A Fuzzy Systematic Approach to Construction Risk Analysis
}

\author{
Babak A. Samani \\ Department of Engineering, California State University \\ East Bay, 25800 Carlos Bee Boulevard, Hayward, CA 94542, USA \\ E-mail: baghaebrahimisamani@horizon.csueastbay.edu \\ Farzad Shahbodaghlou* \\ Department of Engineering, California State University \\ East Bay, 25800 Carlos Bee Boulevard, Hayward, CA 94542, USA \\ *E-mail: farzad.shahbodaghlou@csueastbay.edu \\ Received 4 February 2012 \\ Accepted 20 November 2012
}

\begin{abstract}
This article emphasizes the need for a fuzzy systematic structural approach to the risk assessment of construction projects and introduces the processes required to form a hierarchical systematic structure based on fuzzy logic using the Fuzzy Decision Making Trial and Evaluation Laboratory (Fuzzy DEMATEL) method. In this research, for the first time, the fuzzy DEMATEL method has been successfully applied to the risk assessment of the Persian Gulf Bridge megaproject, connecting Qeshm Island, located in the high risk Strait of Hormuz, to the mainland of Iran, and produced logical results. In this case study, forty-five major risks, classified in ten groups of risks, were found, analyzed, and structured within a systematic hierarchical model. The final causal hierarchical structure of risks has been briefly analyzed and the risks have been prioritized with respect to their values of prominence in the model and their influence on the structure of risk factors. A result of this analysis confirms that country risks, including the state economy and multinational sanctions against the country are the most important risks affecting the project. Another result shows that the most destructive risk can arise from the planning and budgeting of the Sea Bridge project.
\end{abstract}

Keywords: construction risk analysis, fuzzy DEMATEL method, Persian Gulf Bridge, construction risks.

\section{Introduction}

Due to the new integrated approach to the construction project lifecycle and the vast implementation of turnkey contracts, the construction project is newly considered an integrated system rather than one of distinct phases. On the other hand, the number of projects is rapidly increasing every day, especially in developing countries with natural resources. The environment in which the project is executed is becoming ever more complex. In these integrated and complex environment projects, both the number of risks increases, along with the number of interrelationships between them. This increase in the number and interrelationships of risks creates a need for a systematic integrated approach to risk assessment that leads us to the use of systematic group decision making methods, which produce systematic structures of risks and their interrelationships. Because of the fuzzy logic of the human way of thinking, which is to tradeoff between significance and precision, values presented in the procedure of risk assessment, by risk management team members, are not absolute. Due to the recent discussion, fuzzy logic is accepted as a governing theory over the systematic structure.

\section{A Need for a Fuzzy Systematic Approach to Construction Risk Assessment}

In construction projects, since risk factors arise from varying areas, such as political, economic, social, technological and geographical environments, as well as from the project implementation, risk assessment is a group decision making process in which its system 
criteria are risk factors that, even though they come from different areas, intensify each other. In these highrisk projects, in addition to directly impacting the project, individual risks indirectly impact the project objectives through their interrelationships. Thus risks can no longer be classified by a product of two quantities known as probability of occurrence and direct impact on project goals. In other words, the priority of a risk is not determined solely by its prominence, a combination of its direct and indirect impacts on the project goals; rather, the priority of a risk is determined by taking into account both its prominence and its influence on other risks.

This complicated nature of risk prioritization in the uncertain environment of newer projects creates a need for a systematic approach to risk assessment. This systematic approach encourages the use of group decision making based on a pair-wise comparison method in which experts from various areas determine the existence or lack of interrelationships between any pair of risks and the strength of the influence of that relation.

In systematic risk assessment based on pair-wise comparison decision making methods, after risk identification, experts from various areas determine the existence or lack of interrelationships between any pair of risks and the strength of the influence of that relation. That strength of influence is described by a linguistic term such as "none," "very low," "low," "high,” or "very high." These terms are vague statements that are not absolutely precise, however meaningfully understandable and acceptable. Traditionally, systematic group decision making leads to the assignment of a crisp quantity between 0 and 5, rather than the linguistic terms stated.

The human way of thinking conflicts with the traditional assignment method because of its core principles. The human way of thinking is a decision making process that is a tradeoff between precision and significance; the results of this process are vague linguistic terms. Vagueness is a form of epistemic uncertainty that is brought about by the human way of thinking that results in the imprecise meaning of linguistic terms. The tolerance of uncertainty in the process of thinking in human beings proposes that the logic behind the process of thought is logic based on fuzzy truths, fuzzy connectedness and fuzzy rules of inference.

The various factors stated lead to the authorization of fuzzy logic as a governing theory over the systematic structure. Fuzzy logic is a consequence of the developments of fuzzy sets by Lotfi Zadeh, the father of fuzzy logic. A fuzzy set is an extension of a classical (crisp) set. The allowance of membership in crisp sets is either full membership or no membership at all. In other words, in crisp sets an element is pertained to a set or is not pertained to it. Fuzzy sets represent commonsense linguistic labels. A further explanation of fuzzy logic is out of the scope of this paper.

\section{Fuzzy DEMATEL Method}

Decision Making Trial and Evaluation Laboratory, DEMATEL, is a decision making method based on a pair-wise comparison using experts' judgment. This method originated from the Geneva Research Center of Battelle Memorial Institute by Fontela \& Gabus 1976. They developed the DEMATEL method to find integrated solutions for the fragmented and antagonistic phenomena of world societies.

Using the DEMATEL method, and by distinguishing system elements based on the experts' idea generation, incorporating their assessments and judgments, and using the pair-wise comparison matrix and graph theory, a hierarchical structure of elements in a complex system can be achieved in a way that the cause and effect relationship of system elements and the strength of relationships' influence is illustrated in the final structure.

In addition to the practical feature of the DEMATEL method, which is the structural visualization of complex casual relationships with matrix and diagraphs, another advantage of the DEMATEL method over other pairwise comparison methods is that in the hierarchical structure each element can influence all other elements whether they are at the same level, an upper level or a lower level and are capable of being influenced by them. Therefore, the value of each system is assessed by each and every element within that system.

Applying linguistic variables, a fuzzy extension of the DEMATEL method, enables the crisp method to be more appropriate for solving multi- criteria and multiexpert problems in complex and fuzzy environments. Recently, the fuzzy DEMATEL method has been successfully applied in many fields.

For the first time in construction risk assessment, in 2005, Babak A. Samani, successfully applied crisp DEMATEL as a tool for risk assessment in Iranian oil and gas projects and produced logical results. The final hierarchical model was valid and practical for years. Recently, the Fuzzy DEMATEL method was found to be a better approach. Therefore, this method was applied to the Persian Gulf Sea Bridge project. This bridge is located in the Strait of Hormuz and connects Qeshm Island to the mainland of Iran, a high-risk developing country. The DEMATEL method, whether crisp or fuzzy, is of greater service to larger projects than smaller ones due to the fact that risks arisen from various areas and different levels in larger projects have more interrelationships and DEMATEL has the ability to take that into account. 
Chi-Jen Lin and Wei-Wen Wu (2004) clearly explained all essential fuzzy theorems to insure the convergence of this requirement. They discussed the mathematical procedure of computing the total relation fuzzy matrix $\tilde{T}$ as well. The result of their method will suffice to meet our project goal. Based on Lin and Wu's paper, the analytical procedure of the Fuzzy DEMATEL method, omitting theorems and proofs for clarity in application, is described as follows:

\section{Step (1) - Problem Identification, Expert Group, Evaluation Criteria}

The project management team should clearly identify its point of view and the project phase at which the risk assessment is being performed. The authors suggest that this stage occur as part of the feasibility study and economic justification. A group of experts from various fields relating to risks should be formed. Applying one of the idea generation methods within the expert group, they must prepare a list of evaluation criteria, risks or uncertainties.

\section{Step (2) - Fuzzy Pair-Wise Comparison Matrix}

A pair-wise comparison matrix (matrix $\tilde{X}^{(K)}$ ) from the evaluation criteria, which have been identified in step (1), should be generated and presented to the members of the expert group. Then, the experts are asked to make sets of pair-wise comparisons to assign a degree of influence to each cell of matrix $\tilde{X}^{(K)}$. To deal with imprecision of human assessments of causal relations, which have several complicated aspects by nature, $\mathrm{Li}$ R.J. (1999) developed a fuzzy scale with five different degrees of influence. In his proposed fuzzy scale, the degree of influence is one of five linguistic terms $\{$ No, Very low, Low, High, Very High\}. Each linguistic term has its own corresponding positive triangular fuzzy number. In other words, instead of the crisp values, which have been used in the crisp DEMATEL method, experts state their assessments with fuzzy values. The applied fuzzy scale including its linguistic terms and their corresponding positive triangular numbers is shown in table 1.

If a group of $P$ experts is asked to make sets of pairwise comparison, between criteria $C=\left\{C_{i} \mid i=, 1,2, \ldots, n\right\}$ then the number of $P$ pairwise matrixes as $\tilde{X}^{(1)}, \tilde{X}^{(2)}, \ldots, \tilde{X}^{(n)}$, each corresponding to a member of the expert group, will be obtained. The fuzzy scale should be applied to assign corresponding fuzzy numbers to linguistic terms in
$\tilde{X}^{(K)}$ obtained pair-wise comparison matrixes. So pairwise matrix $\tilde{X}^{(K)}$ is denoted as

$$
\tilde{X}^{(K)}=\left[\begin{array}{ccc}
0 & \cdots & \tilde{X}_{1 n}^{(K)} \\
\vdots & \ddots & \vdots \\
\tilde{X}_{k 1}^{(K)} & \cdots & 0
\end{array}\right], K=1,2,3, \ldots, p,
$$

where $P$ is the number of experts $\tilde{X}_{i j}^{(K)}=\left(l_{i j}, m_{i j}, u_{i j}\right)$.

Table 1. Fuzzy scale for pair-wise comparison of evaluation criteria

\begin{tabular}{lccc}
\hline Degree of Influence & $\begin{array}{c}\text { Linguistic } \\
\text { Term }\end{array}$ & Fuzzy Value & $\begin{array}{c}\text { Crisp } \\
\text { Value }\end{array}$ \\
Very High Influence & $(\mathrm{VH})$ & $(0.75,1.0,1.0)$ & 4 \\
High Influence & $(\mathrm{H})$ & $(0.5,0.75,1.0)$ & 3 \\
Low Influence & $(\mathrm{L})$ & $(0.25,0.5,0.75)$ & 2 \\
Very Low Influence & $(\mathrm{VL})$ & $(0,0.25,0.5)$ & 1 \\
No Influence & (No) & $(0,0,0.25)$ & 0 \\
\hline
\end{tabular}

\section{Step (3) - Fuzzy Direct-Relation Matrix}

The direct- relation matrix $\tilde{X}$ is the average matrix of $P$ pair-wise comparison matrixes, which are corresponded to the number of $P$ experts, and calculated by the following formula:

$$
\begin{gathered}
\tilde{x}=\frac{\tilde{x}^{(1)}+\tilde{x}^{(2)}+\tilde{x}^{(3)}+\ldots+\tilde{x}^{(p)}}{p} \\
\text { Fuzzy direct-relation matrix } \tilde{X}_{n \times n} \text { of }
\end{gathered}
$$
criteria $C=\left\{c_{i} \mid i=1,2, \ldots, n\right\}$ is denoted as

$$
\begin{gathered}
c_{1} \\
\tilde{X}_{n \times n}=c_{1} \\
c_{2} \\
\vdots \\
c_{n}
\end{gathered}\left[\begin{array}{cccc}
0 & \tilde{x}_{12} & \cdots & c_{n} \\
\tilde{x}_{21} & 0 & \cdots & \tilde{x}_{2 n} \\
\vdots & \vdots & \cdots & \vdots \\
\tilde{x}_{n 1} & \tilde{x}_{n 2} & \cdots & 0
\end{array}\right]
$$

where $\tilde{X}_{i j}=\left(l_{i j}, m_{i j}, u_{i j}\right)$ are triangular fuzzy numbers. Elements $\tilde{x}_{i j}, i=1,2, \ldots, n$ will be regarded as a triangular fuzzy number $(0,0,0)$ wherever it is necessary.

Step (4) - Normalization 
In order to convert the criteria scales to comparable scales, the liner scale transformation is used to normalize the fuzzy direct- relations matrix.

If $\tilde{X}=\left[\tilde{x}_{i j}\right]_{n \times n}$ and

$\tilde{r}=\sum_{j=1}^{n} \tilde{x}_{i j}=\left(\sum_{j=1}^{n} l_{i j}, \sum_{j=1}^{n} m_{i j}, \sum_{j=1}^{n} u_{i j}\right)$, then

$$
r=\max _{1 \leq i, j \leq n} \tilde{r}=\sum_{j=1}^{n} u_{i j}
$$

Assuming that at least there is one $i$ such that $\sum_{j=1}^{n} u_{i j}\langle r$, then the normalized direct-relation fuzzy matrix denoted by $M$, equals

$\tilde{Z}=r^{-1} \times \tilde{X} \Rightarrow \tilde{Z}=\left(\begin{array}{cccc}\tilde{Z}_{11} & \tilde{z}_{12} & \ldots & \tilde{Z}_{1 n} \\ \tilde{Z}_{21} & \tilde{Z}_{22} & \cdots & \tilde{Z}_{2 n} \\ \vdots & \vdots & \ddots & \vdots \\ \tilde{Z}_{n 1} & \tilde{z}_{n 2} & \cdots & \tilde{Z}_{n n}\end{array}\right)$

where, $\tilde{z}_{i j}=\frac{\tilde{x}_{i j}}{r}=\left(\frac{i_{i j}}{r}, \frac{m_{i j}}{r}, \frac{u_{i j}}{r}\right)$

According to essential definitions, which are given before, the multiplication of two triangular fuzzy numbers results in another triangular fuzzy number. Thus, the elements of matrix $\tilde{M}$ are triangular fuzzy numbers.

\section{Step (5) -Total Relation Fuzzy Matrix}

To figure the total-relation fuzzy matrix $\tilde{T}$ we need to meet the requirement of $\lim \tilde{Z}^{k}=[0]_{n \times n}$ first. According to the crisp DEMATEL method, the total relation matrix $\tilde{T}$ is defined as

$\tilde{T}=\lim _{k \rightarrow \infty}\left(\tilde{Z}^{1}+\tilde{Z}^{2}+\ldots+\tilde{Z}^{K}\right)$

when $\lim \tilde{Z}^{k}=[0]_{n \times n}$. Let define three crisp matrixes, whose elements are extracted from $\tilde{Z}$, as $Z_{l}=\left(\begin{array}{cccc}0 & l_{12} & \ldots & l_{1 n} \\ l_{21} & 0 & \cdots & l_{2 n} \\ \vdots & \vdots & \ddots & \vdots \\ l_{n 1} & l_{n 2} & \cdots & 0\end{array}\right)$

$Z_{m}=\left(\begin{array}{cccc}0 & m_{12} & \ldots & m_{1 n} \\ m_{21} & 0 & \cdots & m_{2 n} \\ \vdots & \vdots & \ddots & \vdots \\ m_{n 1} & m_{n 2} & \cdots & 0\end{array}\right)$
$Z_{u}=\left(\begin{array}{cccc}u_{11} & u_{12} & \ldots & u_{1 n} \\ u_{21} & 0 & \cdots & u_{2 n} \\ \vdots & \vdots & \ddots & \vdots \\ u_{n 1} & u_{n 2} & \cdots & 0\end{array}\right)$

and

$\tilde{T}=\left(\begin{array}{cccc}\tilde{t}_{11} & \tilde{t}_{12} & \cdots & \tilde{t}_{1 n} \\ \tilde{t}_{21} & \tilde{t}_{22} & \cdots & \tilde{t}_{2 n} \\ \vdots & \vdots & \ddots & \vdots \\ \tilde{t}_{n 1} & \tilde{t}_{n 2} & \cdots & \tilde{t}_{n n}\end{array}\right)$

where

$\tilde{t}_{i j}=\left(L{ }_{i j}, m^{*}{ }_{i j}, u^{\prime i j}\right)$,

And

$\left[L_{i j}^{\prime \prime}\right]=Z_{i} \times\left(I-Z_{i}\right)^{-1}$

$\left[m_{i j}^{\prime \prime}\right]=Z_{m} \times\left(I-Z_{m}\right)^{-1}$

$\left[u_{i j}^{\prime \prime}\right]=Z_{u} \times\left(I-Z_{u}\right)^{-1}$

Step (6) - Prominence and Influence of Each Criterion, Hierarchical Structure

Assuming $\tilde{D}_{i}$ and $\tilde{R}_{i}$ are the sum of columns and the sum of the rows of matrix $\tilde{T}$, respectively, the prominence of each criterion can be obtained by adding $\tilde{D}_{i}$ to $\tilde{R}_{i}$ and the influence of each criterion is calculated by subtracting $\tilde{R}_{i}$ from $\tilde{D}_{i}$. To acquire the causal diagram one of the defuzzification methods should be applied. Then, the causal diagram and analysis will be drawn like crisp DEMATEL method just by assigning $\left(\tilde{D}_{i}+\tilde{R}_{i}\right)^{\text {def }}$ and $\left(\tilde{R}_{i}-\tilde{D}_{i}\right)^{\text {def }}$ values to the horizontal and vertical axis's, respectively.

\section{Persian Gulf Sea Bridge Project}

The Persian Gulf Sea Bridge's project objectives are construction of a bridge facility including marine, civil, structural, piping, electrical and any other necessary amenities and equipment to transport cars, trucks, trains, water, oil, gas and liquid products transporting pipe lines and cable connections (electricity, telecommunications, internet)from Qeshm Island to Iran's main land and vice versa.

The specific location of Qeshm Island in the Strait of Hormuz, makes it important for the Iranians. The Strait of Hormuzis a narrow waterway to the Persian Gulf, 
which is the most significant region of oil, gas, petrochemicals and minerals in the world.

Iran is an underdeveloped country in which several huge construction projects, such as oil and gas field developments, urban developments, power plants, dams, infrastructure improvements, and etc. are being planned and implemented. Due to the Importance of Qeshm Island for the country, there are many development plans that are being designed and executed on the Island and its surrounding.

\section{Project Risks}

Based on field studies and experts opinions, 45 major risks to the general contractor in the Persian Gulf Bridge project affecting the company's engagement in the project have been identified from the private general contractor's point of view at the very early stage of the project. Then, based on the most important feature of each risk, they have been classified into 10 risk categories as shown in Table 2. Explanation of all the risk factors is beyond the scope of this paper. Risk categories are briefly explained in the following:

\subsection{Country risks}

According to Advanced Engineering Associate International (AEAI) "Country Risk is a particularly general term, which refers to risks affecting all companies operating within a particular country. Primarily, it refers to the risk of investing in a country. Major country risks of Iran that affect the Persian Gulf Bridge project are as follows.

- Multinational sanctions

- Possibility of regional war or conflicts

- State economy

- Political instability of the government

- High inflation rate

- Recession

- Corruption

- Out of date labor, tax, insurance, trade and environment laws

- Slow process of governmental permits issuance

- Slow and costly customs process

- Incapable IT infrastructure

\subsection{Companies' capabilities risks}

The success of a project depends on the capabilities of its participant companies, the project's executive system, and the existing infrastructure, inclusive of legal, informative, cultural, and educational infrastructures.

As a matter of fact, many project risks, which are usually called company's internal risks, arise from within company parameters that compose the capability of a company. Company's capability is defined by parameters such as: strategy, policy, cash flow, organizational structure, management systems, and Information Technology infrastructure. It also requires leadership, skills and proficiency, personnel motivation and organizational culture. The more successful management operations are in these areas, the more a company's capability will increase and the fewer hazards will arise.

There are complex direct and indirect causal relationships between component parameters of a company's capability, elements of its executive system and infrastructural factors of the environment in which the project is implemented. Also, unsatisfactory results in time, quality, and cost of project implementation result in a drop in client/ governmental confidence levels causing that company to lose future projects and consequently intensifying the company's weakness. See figure 1. Due to several causal relationships within the system shown in figure 1 , an extensive research is required to analyze the risks arisen from internal factors of a company. Also, due to the large size of this research, the feedback links from project results are not taken into account.

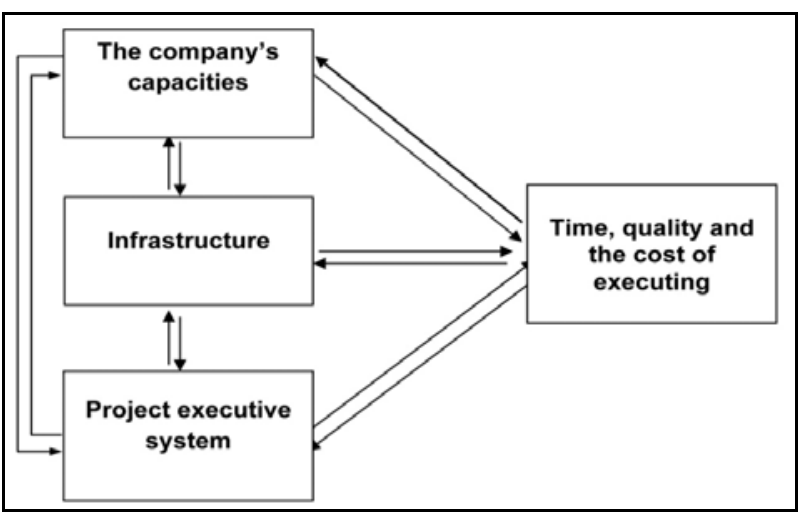

Fig. 1.The effective parameters in projects success

Risks associated with companies' capabilities in Persian Gulf Bridge project are as follows.

- Low level capability of contractors

- Lack of powerful foreign companies to participate in domestic projects

\subsection{Management risks}

Risks associated with ineffective, destructive or underperforming management, which affects project goals are called management risks. Management risks refer to the risks of the circumstance in which project parties would have been better off without the choices made by management. Basically, management risks refer to the chance that project managers will put their own interests ahead of the interest of the project 
stakeholders and project goals. Major management risks in Persian Gulf Bridge project are as follows.

- Frequent replacement of project managers

- Poor management

- Debility in project planning and budgeting

- Delay in choosing contractors and consultants

\subsection{Human capital risks}

Construction projects essentially are reliant on people to succeed. Employees, the human capital asset, with the right skill profile and capability, are one of the critical success factors of projects. According to Seymour Adler, (2008); human capital risk is employee-related events or behaviors that can affect the operations and/or value of the company. These risks may be generated by activities either inside or outside the workplace.

Major human capital risks in Iran are as follows:

- Lack of professional and developed manpower

- Low level motivation and efficiency of existing manpower

- Low efficiency of training programs

- Debility in hiring foreign professionals

\subsection{Financial risks}

Advanced Engineering Associate International (AEAI, 2010) defines financial risks as follows; "financial risks are associated with any form of financing and reflect the uncertainty of whether the return on an investment will be less than that required for the repayment of lending”. Lack of funds to provide the necessary budget to manage costly construction projects along with the emergence of financial problems during project execution are the primary challenge facing Iranian industry. Risks arisen from project financing area are as follows.

- Insufficient economic justification

- Weakness of banking system

- Absence of foreign banks

\subsection{Insurance risks}

Insurance risks reflect the uncertainty of insurance and bonding. Since the low capable Iranian companies fail to meet the project primary goals, many insurance companies refuse to insure their projects. Risks associated with project insurance in Iranian construction projects are as follows.

- Weakness of bonding and insurance companies

- Absence of foreign bonding and insurance companies

\subsection{Procurement risks}

Risks originating from procurement activities are known as procurement risks. In huge projects $40 \%$ to $60 \%$ of budget is assigned to procurement activities. Thus, risks associated with procurement activities have huge impacts on project primary goals. Major procurement risks in Persian Gulf bridge project are as listed below.

- Low quality of domestic products

- Manufacturers' debility in manufacturing of some project equipment

- Obstacles of abroad procurement

- Impediments of software purchasing

\subsection{Health, safety and environmental risks}

Similar to all construction projects, health, safety and environmental (HSE) risks are highlighted in Persian Gulf Bridge project. Lack of health and safety culture within Iranians makes the situation worse. Because of unique environment of site location and pure tourist attractions, environmental risks are highly required to be taken into consideration. Two major risks arisen from HSE area are as listed below.

- Insufficiency of health, safety and environmental regulations

- High risk project in terms of health, safety and environmental risks

\subsection{Site Condition risks}

Differing site conditions has always been an issue in construction contracts. Hence, risks arisen from site condition should be taken into account in terms of risk assessment. Major site condition risks are as follows.

- Geotechnical risks (Intertidal zones floored by unconsolidated sandy mud and clay, over laid on marine calcareous terraces)

- Earthquake-prone area

- Hydrological risks (Tsunami waves, strong two-way water -flow and high water - salinity)

- Mangrove forests

- Traffic of large vessels and huge ships

- Distance from primary sources and materials

- Distances from major manufacturers which are concentrated in central states

\subsection{Design, construction, operation and maintenance risks}

This category of risks is all about risks arisen during the project implementation; those are more affected by the other risk categories and have less impact on them. These types of risks are very typical so that they can be identified in all construction projects. Main execution risks in Persian Gulf Bridge are listed below.

- Lack of experience in this type of project

- Design risks

- Change orders

- Force majeure

- Operational risks 


\section{- Maintenance risks}

\section{Applying the Fuzzy DEMATEL Method to the Persian Gulf Sea Bridge Project}

In this research, the Fuzzy DEMATEL method has been applied twice. One time it was applied for all 45 risks of the project, while another time it was applied for only the 10 major risks. For brevity, the risk categories and application for the risk categories will be discussed. Applying step 2 of the fuzzy DEMATEL method, the fuzzy pair-wise comparison matrix has been obtained and shown in figure 2 . The comparison matrix reflects the strength of influence of each risk category on the other risk categories by the linguistic terms. The authors believe that while the project risks gradually damage the project primary goals (time, cost, quality and safety), the back influences from the project primary goals on the project risks intensify the project risks Subsequently. In other words, there are bilateral relationships between the project risks and the project's primary goals. Since discussion about this novel idea is beyond the scope of this research, the back influences from primary goals on risk categories are not taken into account. Nevertheless, the final hierarchical model is still valid, because the back influences have very low strengths plus risk analyzers unconsciously consider the back influences during the pair-wise comparison between risk categories. There are also interrelationships between cost, quality, time, and safety, which are to be taken into account in the risk assessment process. Since different risks have different direct and indirect effects on each of the project objectives that in turn has different influences on the rest of project objectives, the project management team should prioritize the project goals and make a trade-off between cost, time, quality and safety throughout the risk assessment process. Otherwise the risk prioritization will not be sensible. The trade-off between project goals is done in lower right cells of pair-wise comparison matrix 1.

Using MATLAB programming software and assigning the corresponding positive triangular numbers, specified in table 1 , to the given linguistic terms of comparison matrix 1 and completing the method's steps, the fuzzy values of $\tilde{W}=\left(\tilde{R}_{i}+\tilde{D}_{i}\right)$ and $\tilde{Q}=\left(\tilde{R}_{i}-\tilde{D}_{i}\right)$ have been calculated for each risk category. Using defuzzification operation, the crisp values of $\mathrm{W}$ and $\mathrm{Q}$ have been obtained. Tables 3 and 4 show the fuzzy and crisp vales of $\tilde{W}$ and $\tilde{Q}$ for each risk category, respectively.

As discussed in step 6 of the fuzzy DEMATEL method, the crisp values of $\mathrm{W}$ and $\mathrm{Q}$ should be assigned to the horizontal and vertical axis of coordinating system of final hierarchical model, respectively. The final hierarchical model has been acquired by mapping the dataset of $\left(W_{\text {def }}, Q_{\text {def }}\right)$ proving final systematic structure of the risk categories. Figure 3 demonstrates the final hierarchical model.

Table 2. Project risk categories and risks

\begin{tabular}{|c|c|c|}
\hline No & RISKS & Code \\
\hline \multicolumn{2}{|c|}{ Country Risks } & $\mathrm{CN}$ \\
\hline 1 & Multinational sanctions & $\mathrm{CN} 01$ \\
\hline 2 & Possibility of regional war or conflicts & $\mathrm{CN} 02$ \\
\hline 3 & State economy & $\mathrm{CN} 03$ \\
\hline 4 & Political instability of the government & $\mathrm{CN} 04$ \\
\hline 5 & High inflation rate & $\mathrm{CN} 05$ \\
\hline 6 & Recession & $\mathrm{CN} 06$ \\
\hline 7 & Corruption & $\mathrm{CN} 07$ \\
\hline 8 & Out of date labor, tax, insurance, trade and environment laws & $\mathrm{CN} 08$ \\
\hline 9 & Slow process of governmental permits issuance & $\mathrm{CN} 09$ \\
\hline 10 & Slow and costly customs process & $\mathrm{CNl} 0$ \\
\hline 11 & Incapable IT infrastructure & $\mathrm{CNII}$ \\
\hline \multicolumn{2}{|r|}{ Companies' Capabilities Risks } & CM \\
\hline 12 & Low level capability of contractors & CM01 \\
\hline 13 & Lack of powerful foreign companies to participate in Iranian projects & $\mathrm{CM} 02$ \\
\hline \multicolumn{2}{|c|}{ Management Risks } & MG \\
\hline 14 & Frequent replacement of project managers & MG01 \\
\hline 15 & Poor management & MG02 \\
\hline 16 & Debility in project planning and budgeting & MG03 \\
\hline 17 & Delay in choosing contractors and consultants & MG04 \\
\hline \multicolumn{2}{|r|}{ Human Capital Risks } & $\mathrm{HC}$ \\
\hline 18 & Lack of professional and developed manpower & $\mathrm{HCOI}$ \\
\hline 19 & Low level motivation and efficiency of existing manpower & $\mathrm{HC} 02$ \\
\hline 20 & Low efficiency of training programs & $\mathrm{HC} 03$ \\
\hline 21 & Debility in hiring foreign professionals & $\mathrm{HC} 04$ \\
\hline \multicolumn{2}{|c|}{ Financial Risks } & FN \\
\hline 22 & Insufficient economic justification & FN01 \\
\hline 23 & Weakness of banking system & FN02 \\
\hline 24 & Absence of foreign banks & FN03 \\
\hline \multicolumn{2}{|c|}{ Insurance Risks } & IN \\
\hline 25 & Weakness of bonding and insurance companies & IN0I \\
\hline 26 & Absence of foreign bonding and insurance companies & IN02 \\
\hline \multicolumn{2}{|c|}{ Procurement Risks } & PR \\
\hline 27 & Low quality of domestic products & PR01 \\
\hline 28 & Manufacturers debility in manufacturing of some project equipments & PR02 \\
\hline 29 & Obstacles of abroad procurement & PR03 \\
\hline 30 & Impediments of software purchasing & PR04 \\
\hline \multicolumn{2}{|r|}{ Health, Safety and Environmental Risks } & HS \\
\hline 31 & Insufficiency of health, safety and environmental regulations & $\mathrm{HS} 0 \mathrm{I}$ \\
\hline 32 & High risk project in terms of health, safety and environmental risks & $\mathrm{HS} 02$ \\
\hline \multicolumn{2}{|r|}{ Site Condition Risks } & $\mathrm{SC}$ \\
\hline 33 & Geotechnical risks & SC0I \\
\hline 34 & Earthquake-prone area & $\mathrm{SC} 02$ \\
\hline 35 & Hydrological risks & $\mathrm{SC} 03$ \\
\hline 36 & Hara forests & SC04 \\
\hline 37 & Traffic of large vessels and huge ships & SC05 \\
\hline 38 & Distance from primary sources and materials & SC06 \\
\hline 39 & Distances from major manufacturers which are concentrated in central states & SC07 \\
\hline \multicolumn{2}{|r|}{ Design, Construction, Operation and maintenance Risks } & DB \\
\hline 40 & Lack of experience in this type of project & DB0I \\
\hline 41 & Design Risks & DB02 \\
\hline 42 & Change orders & DB03 \\
\hline 43 & Force Majeure & DB04 \\
\hline 44 & Operation Risks & DB05 \\
\hline 45 & Maintenance Risks & DB06 \\
\hline
\end{tabular}

\section{Analyzing the Final Systematic Structure of Risk Categories}

The crisp value of $\mathrm{W}$ indicates weight of each risk category importance and the crisp value of $\mathrm{Q}$ specifies influence of each risk category and divides the risk categories into a cause or effect group. When $\mathrm{Q}$ is 
positive, the risk category belongs to the cause group. Otherwise, if the $\mathrm{Q}$ is negative, the risk category belongs to the effect group.

In the top right hand part of figure 3 where the highest values of $\mathrm{W}$ and $\mathrm{Q}$ of risks exist $(\mathrm{W}=1.67, \mathrm{Q}=1.17)$, country risks (CN) having the high prominence in model, would be less affected by the other risks within the system, but would influence them strongly. Hence, to mitigate country risks, we should directly use external areas from the final model. Addressing these big risks, which affect 90 percent of other criteria within the final model directly and intensively, would be a great help in mitigating the most of risks.

At the right hand side of the coordinate system, where we see the highest number of $W$ and $a$ relatively large amount of $\mathrm{Q}$, management risks (MG) are placed $(\mathrm{W}=1.85, \mathrm{Q}=0.60)$. Occupying the area of highest prominence values, management risks are the most important risks of Persian Gulf bridge project and highly intensify the other project risks. In addition, management risks are also tremendously influenced by the other risks because of their large value of $Q$. Many practices show that numbers of management risks are originated from country risks. Due to the vertical

\begin{tabular}{|c|c|c|c|c|c|c|c|c|c|c|c|c|c|c|c|}
\hline RiskCatogy & & $\mathrm{CN}$ & CM & MG & $\mathrm{HC}$ & FI & $\mathbb{N}$ & $P 8$ & $\mathrm{HS}$ & $s$ & $D B$ & $T$ & $c$ & $Q$ & $\mathrm{HSO}$ \\
\hline Couth Ridis & aN & No & VH & VH & VH & VH & VH & Vit & $V_{H}$ & No & H & $\mathrm{VH}$ & $\mathrm{VH}$ & H & l \\
\hline Congunis' Canobilitis Rids & an & n. & 10 & n. & $t$ & 1 & 1 & H & $\mathrm{n}_{\mathrm{n}}$ & $\mathrm{No}_{0}$ & VH & $\mathrm{VH}$ & VH & VH & VH \\
\hline Manzagment Rists & MG & n & $\mathrm{VH}$ & 10 & $\mathrm{H}$ & n & n & H & VH & $\mathrm{No}$ & VH & $\mathrm{H}$ & $\mathrm{H}$ & $\mathrm{H}$ & $\mathrm{VH}$ \\
\hline Himan Capial Róds & $\mathrm{HC}$ & n & H & $\mathrm{H}$ & $\mathrm{No}$ & n & V & V. & $\mathrm{VH}$ & 10 & VH & 1 & 1 & $\mathrm{H}$ & $\mathrm{VH}$ \\
\hline Francill Rists & FN & l & $\mathrm{VH}$ & H & $\mathrm{No}$ & No & VH & Vit & $\mathrm{No}$ & $\mathrm{No}$ & $\mathrm{VH}$ & $\mathrm{VH}$ & $\mathrm{VH}$ & $\mathrm{H}$ & \\
\hline Insurnace Risis & $\mathbb{N}$ & n. & H & 1 & $\mathrm{No}$ & 1 & No & Vit & n & $\mathrm{No}$ & 1 & $\mathrm{H}$ & $\mathrm{H}$ & $\mathrm{H}$ & VH \\
\hline Prosinment Rises & $P R$ & Mo & 1 & 1 & $N_{0}$ & 1 & VL & $\mathrm{No}_{0}$ & n. & 110 & $\mathrm{VH}$ & $\mathrm{VH}$ & $\mathrm{VH}$ & $\mathrm{VH}$ & 1 \\
\hline Hilath, Stefry and Envivemental Rists & 45 & 10 & $\mathrm{No}$ & n. & n. & $\mathrm{No}$ & VL & $\mathrm{No}$ & 10 & 10 & n. & n. & n. & VI & VH \\
\hline Sire Condition Rists & sc & No & $\mathrm{NO}_{0}$ & $\mathrm{No}$ & n & n & V. & i & $\mathrm{H}$ & $\mathrm{No}$ & VH & $\mathrm{H}$ & $\mathrm{H}$ & $\mathrm{H}$ & 10 \\
\hline Desizn, Costroction, Opertion \& Mainten & DB & $\mathrm{N}_{0}$ & $\mathrm{No}$ & 1 & $\mathrm{No}$ & $v_{1}$ & $\mathrm{~nL}_{\mathrm{L}}$ & 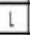 & $\mathrm{H}$ & 10 & 110 & $\mathrm{VH}$ & $\mathrm{VH}$ & $\mathrm{VH}$ & $v_{n-1}$ \\
\hline Tine & $T$ & $\mathrm{No}$ & 10 & 110 & $\mathrm{No}$ & $\mathrm{No}$ & $\begin{array}{lll}\mathrm{No} \\
\end{array}$ & $\mathrm{No}$ & $\mathrm{No}$ & 10 & $1 \mathrm{No}$ & $\mathrm{No}$ & $\mathrm{VH}$ & $\mathrm{H}$ & 1 \\
\hline $\cos$ & $c$ & \begin{tabular}{|l|}
$N_{0}$ \\
\end{tabular} & \begin{tabular}{|l|l|}
10 \\
\end{tabular} & 110 & $\mathrm{No}$ & $\mathrm{No}$ & $\begin{array}{lll}N o \\
\end{array}$ & $N_{0}$ & $1 \mathrm{No}$ & $1 \mathrm{~N}_{0}$ & $\mathrm{No}$ & $\mathrm{VH}$ & 10 & $\begin{array}{ll}\mathrm{H} \\
\end{array}$ & 1 \\
\hline Qjify & $Q$ & 100 & 100 & $\mathrm{No}$ & $\mathrm{No}$ & $\mathrm{No}$ & $N_{0}$ & $\mathrm{No}$ & $\mathrm{No}$ & $\begin{array}{lll}N_{0} \\
\end{array}$ & $\mathrm{No}$ & $\mathrm{I}$ & $\begin{array}{ll}\mathrm{H} \\
\end{array}$ & $\mathrm{No}$ & $I$ \\
\hline HSEE & 1556 & $\mathrm{~N}_{0}$ & 10 & $\mathrm{No}$ & $\mathrm{No}$ & $\mathrm{No}$ & $\mathrm{No}$ & $\mathrm{No}_{0}$ & 110 & 10 & $\mathrm{No}$ & n. & v. & $\begin{array}{ll}\mathrm{V} \\
\end{array}$ & No \\
\hline
\end{tabular}

Fig.2. Pair-Wise Comparison Matrix of Risk Categories

Tables 3. Fuzzy and crisp values of $\tilde{Q}=\left(\tilde{R}_{i}-\tilde{D}_{i}\right)$ for risk categories

\begin{tabular}{|c|c|c|c|c|c|c|}
\hline \multirow{2}{*}{ RISK } & \multicolumn{3}{|c|}{ Q } & \multicolumn{3}{|c|}{ W } \\
\cline { 2 - 7 } & $\mathrm{I}$ & $\mathrm{m}$ & $\mathrm{u}$ & $\mathrm{I}$ & $\mathrm{m}$ & $\mathrm{u}$ \\
\hline CN & 0.31 & 1.37 & 2.15 & 0.93 & 1.73 & 2.77 \\
\hline CM & -0.49 & 0.45 & 1.39 & 0.86 & 1.62 & 2.74 \\
\hline MG & -0.45 & 0.58 & 1.62 & 0.82 & 1.67 & 2.88 \\
\hline HC & -0.30 & 0.65 & 1.57 & 0.58 & 1.28 & 2.45 \\
\hline FN & -0.18 & 0.78 & 1.70 & 0.82 & 1.61 & 2.70 \\
\hline IN & -0.44 & 0.46 & 1.52 & 0.62 & 1.40 & 2.58 \\
\hline PR & -0.70 & 0.15 & 1.12 & 0.79 & 1.51 & 2.61 \\
\hline HS & -0.98 & -0.29 & 0.67 & 0.38 & 0.94 & 2.03 \\
\hline SC & -0.02 & 0.73 & 1.47 & 0.35 & 0.73 & 1.83 \\
\hline DB & -0.88 & -0.15 & 0.86 & 0.90 & 1.61 & 2.65 \\
\hline T & -1.96 & -1.16 & -0.46 & 0.89 & 1.61 & 2.39 \\
\hline C & -1.96 & -1.20 & -0.49 & 0.92 & 1.65 & 2.39 \\
\hline Q & -1.98 & -1.06 & -0.38 & 0.85 & 1.55 & 2.45 \\
\hline HSE & -2.11 & -1.29 & -0.58 & 0.74 & 1.45 & 2.27 \\
\hline
\end{tabular}

Tables 4. Fuzzy and crisp values of $\tilde{W}=\left(\tilde{R}_{i}+\tilde{D}_{i}\right)$ for risk categories

\begin{tabular}{|c|c|c|}
\hline RISK & Wdef & Qdef \\
\hline CN & 1.67 & 1.17 \\
\hline CM & 1.64 & 0.42 \\
\hline MG & 1.85 & 0.60 \\
\hline HC & 1.34 & 0.60 \\
\hline FN & 1.61 & 0.72 \\
\hline IN & 1.50 & 0.50 \\
\hline PR & 1.50 & 0.17 \\
\hline HS & 0.92 & -0.16 \\
\hline SC & 0.72 & 0.54 \\
\hline DB & 1.50 & -0.05 \\
\hline T & 1.23 & -0.90 \\
\hline C & 1.22 & -0.90 \\
\hline Q & 1.29 & -0.91 \\
\hline HSE & 1.14 & -1.02 \\
\hline
\end{tabular}

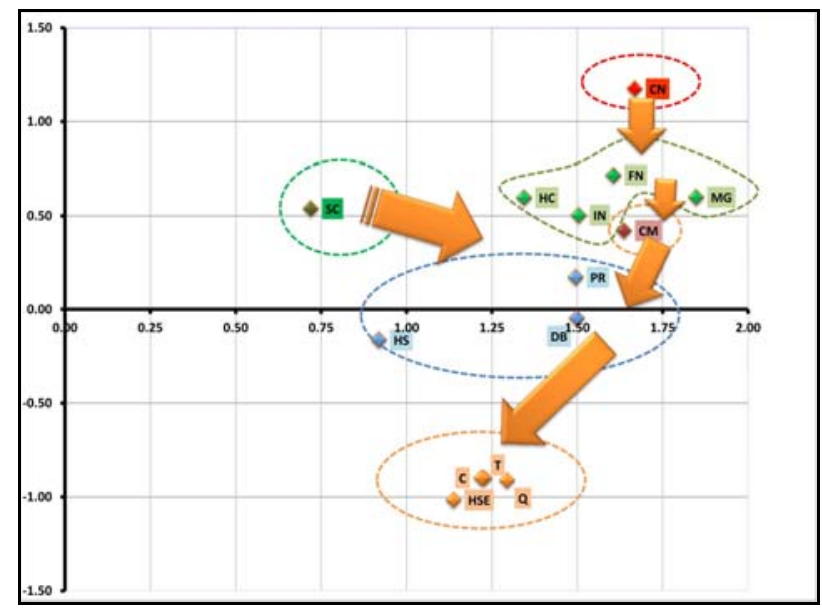

Fig.3. The final systematic structure of risk categories

location of human capital risks (HC) and financial risks (FN) between country risks (CN) and management risks (MN) in the coordinate system, it is inferable that similar to every other project the management risks (MN) are largely influenced by country risks (CN) before by the other risks.

Two major factors of any management system are human capital and financial capital. Thus any risk associated with these two areas can influence the management system. This concept is illustrated well in the final hierarchical model. Locations of these two categories of risks in figure 3 perfectly demonstrate this hypothesis.

The capability of a construction company is associated with its management system, financial and human capitals and insurance resources. If we look at the place of contractors' capabilities risks (CM) in figure 3, we 
can see that the contractors' capability risks (CM) are located in the middle of the casual diagraph. This category of risks is influenced by the lack of sufficient human (HC) and financial (FN) capitals as well as management risks. Companies' capabilities risks also influence the risks arisen from project execution process such as procurement, design, construction, health and safety, environmental, operational and maintenance risks.

Noticing the positions of the design, build and operational (DB) risks category and the health, safety and environmental risks category (HS), both risk categories have negative values of influence $(Q<0)$ which indicate that these categories of risks belong to the effect group of casual diagraph. Although the influence value of procurement risks category (PR) is positive, it is still very close to the other project execution risks (DB and HS). Thus procurement risks might belong to the effect group of risks if they are evaluated comparison to all other 41 risks. Generally project execution risks are highly influenced by upstream risks such as procurement, construction, operational and maintenance risks. Risks associated with the project implementation process have a lower value of prominence than the upstream risks such as country, management, finance and human capital and companies' capabilities risks and have less back influence on them. As it is shown in figure 3, since the risk assessment has been done at the early stages of the Persian Gulf Bridge project, the health, safety and environmental risk category (HS) has less value of prominence comparison with the other risks originated from project execution process (DB and PR).

At the mid-left side of figure 3, where we see the positive calculated amounts of influence $(Q>0)$ and small values of prominence $(W \leq 0.75)$, the category of site condition risks (SC) is located. Typically, site conditions risks (SC) are independent risks that do not receive major influence from other risk categories. Due to their positive influence strength $(Q=0.54)$, site condition risks, however, have significant influences on the several risks associated with project implementation system in the areas of design, procurement and construction. Site condition risks also intensify the planning and budgeting risks and have some effects on risks associated with companies' capabilities.

\subsection{Trade-off between project objectives}

At the lowest level of figure 3, with the most negative values of $\mathrm{Q}$, the project objectives are strongly impacted by the project risks. In this area, the health, safety and environment (HSE) goal is located in the lower left position of the other objectives. This means that the
HSE goal is the least important and the most impacted project objective. There are many problems that should be resolved to mitigate the HSE risk and there is a danger of abandonment of this goal. Cost objective (C) has taken a place slightly below the time objective and on its left side. Since the time goal $(\mathrm{T})$ has a higher position than the other project objectives, it can be inferred that governmental stakeholders of project are extremely concern about meeting the project milestones. This could be due to their effort to take a partisan advantage of the sea bridge project in the approaching presidential election in 2012.

The project's quality objective (Q) is located on the bottom right side of the casual diagraph. Although the quality objective has a relatively large value of prominence, it is in danger to be scarified for the other project's goals because of its highly negative value of influence.

Arrows drawn in the coordinating system (figure 3) help with the understanding of influence flow in the casual diagraph. Obviously a DEMATEL model is not adjustable from bottom up.

\section{Conclusion and Recommendation}

\subsection{Conclusion}

After reviewing the concept of uncertainty, risk, and fuzzy logic, the authors concluded that the logic inspiring risk assessment is neither absolute nor probabilistic, rather that it is fuzzy. The authors strongly believe that the traditional decision making methods widely used in the risk assessment process are better when shifted to fuzzy operations. Due to the new integrated approach to the construction project lifecycle and the vast implementation of turnkey contracts, construction project is newly considered an integrated system rather than one of distinct phases. On the other hand, the number of megaprojects is increasing every day, especially in developing countries with natural resources. The environment in which the project is executed is becoming ever more complex. In theses integrated and complex environment of megaprojects, the number of risks increases, along with the number of interrelationships between them. This increase in the number and interrelationships of risks creates a need for a systematic integrated approach to risk assessment that leads us to the use of systematic group decision-making methods. This in turn produces systematic structures of risks and their interrelationships. Because of the fuzzy logic of the human way of thinking, which is to tradeoff between significance and precision, values presented in the procedure of risk assessment, by risk management team members, are not absolute. Due to the recent 
discussions, fuzzy logic is accepted as a governing theory over the systematic structure.

In this research, for the first time, the fuzzy DEMATEL method has been successfully applied to the megaproject of the Persian Gulf Bridge project and has produced logical results. In this case study, forty-five major risks, classified in ten groups of risks, were found, analyzed, and structured within a systematic hierarchical model. A result of this analysis confirms that country risks, including political instability of the government, the state economy, and multinational sanctions against the country are the most important risks affecting the project. Another result shows that the most serious risk can arise from the planning and budgeting of Sea Bridge project.

Trading-off between project goals is an activity that should be done in the process of risk analysis, applying pair-wise comparison methods. The casual relationships between the project objectives should be taken into account because each of the project objectives can be impacted by any direct impact of each risk and by the indirect impact of risks through the other project goals.

The use of the fuzzy DEMATEL method in risk assessment is highly recommended.

\section{2 - Recommendations for Further Research}

First, evaluating the validation of the final hierarchical model structured in this research can be a new topic. Applying neural network models can be an approach to this evaluation.

Secondly, defining fuzzy functions for the project objectives and their relationships with project risks can be done as further research.

Thirdly, complementary research can follow this project so that the back-influences from the project goals on the risks are taken into account.

\section{References}

1. Babak A. Samani (2012). "Applying the Fuzzy DEMATEL Method to the Risk Analysis of Construction Projects". M.S. Thesis, California State University East Bay.

2. Rong- Jun Li (1999). "Fuzzy Method in Group Decision Making”. Department of Decision Science, Central South University Changsha, Hunan 410083, P.R. China

3. Chi-Jen Lin, Wei-Wen Wu (2004). "A Fuzzy Extension of the DEMATEL Method for Group Decision-Making”, Department of Industrial Engineering and Management, Ta Hwa Institute of Technology.

4. Advanced Engineering Associates International, Inc. (AEAI) (2010) - Sheberghan Gas Field Development Plan Risk Analysis Report - http://www.sheberghangas.com

5. Seymour Adler, Amy Mills \& Matt Shadrick (2008) - Why You Should Be A Human Capital Risk Manager - AON Consulting \& Kellogg School of Management 